\title{
Experimental and numerical simulation of flow over stepped spillways
}

\author{
Farzin Salmasi ${ }^{1}$ [ $\cdot$ Aylar Samadi $^{2}$
}

Received: 9 February 2018 / Accepted: 8 November 2018 / Published online: 17 November 2018

(c) The Author(s) 2018

\begin{abstract}
Stepped spillways are used in the construction of dams, river engineering and soil conservation projects. Energy dissipation in this structure due to the presence of several steps is high, so the construction costs for stilling basin are reduced. The numerical models are new method for flow analysis. This study investigates the flow on the stepped spillway and calculates energy loss caused by it. Also in this study, fluctuation of velocity vectors, shear stress and pressure during the flow on each step is compared. For this purpose, a physical model of the stepped spillway was built with slope at a ratio of 2:1 (horizontal to vertical) and experiments were performed with ten different flow rates. The numerical simulations also were performed under the same conditions using FLUENT software and RNG $k-\varepsilon$ turbulence model. Finally, the results of the numerical model were compared with experimental data. The results indicate that numerical model is in reasonable consistency with the physical model and it can be used in anticipation complex rotational flows in the stepped spillway.
\end{abstract}

\section{Keywords Energy dissipation $\cdot$ Velocity vector $\cdot$ Shear stress $\cdot$ Pressure $\cdot$ Stepped spillway $\cdot$ Numerical $\cdot$ FLUENT}

\section{List of symbols}

$g_{x i} \quad$ Gravitational acceleration components

$H$ Total height of spillway

$H_{0} \quad$ Water energy above the spillway crest

$H_{1} \quad$ Water energy at downstream of the spillway before the hydraulic jump

$q \quad$ Discharge per unit width of spillway

$K \quad$ A dimensionless parameter where

$K=\left(H_{0}-H_{1}\right) / H_{0}$

$\bar{p} \quad$ A pressure term at each point of the fluid

$V_{\text {a }} \quad$ Approach velocity of water to the spillway

$t \quad$ Time

$\overline{u_{i}} \quad$ Velocity component in the direction $x_{\mathrm{i}}$

$y \quad$ Water depth at a distance of about $60 \mathrm{~cm}$ on upstream

$y_{\mathrm{c}} \quad$ Oritical depth where $y_{\mathrm{c}}=\left(q^{2} / g\right)^{1 / 3}$

$\nu \quad$ Kinematic viscosity of water

$\rho \quad$ Water density

$\tau \quad$ Shear stress in bottom of spillway step

Farzin Salmasi

Salmasi@tabrizu.ac.ir

Aylar Samadi

a_samadi10@yahoo.com

1 Department of Science and Water Engineering, Faculty of Agriculture, University of Tabriz, Tabriz, Iran

2 University of Tabriz, Tabriz, Iran

\section{Introduction}

Stepped spillways are important as structures for energy dissipation at the downstream of dams. One of the important principles on the study of the flow in downstream of dams is energy dissipation. According to equation which was provided by Torricelli, maximum flow rate in downstream of the dam is equal to $\sqrt{2 g h}$, where $h$ is the difference between depths of water in upstream and downstream. However, due to the surface friction, velocity will be less than the above amount and the ratio of the real velocity to the maximum flow velocity depends on the type of the channel that fluid passes it. This reduction in flow velocity will be caused as a part of energy dissipation of flow. So, if we can disperse the energy of flow over the spillway monotonically and continuous by increasing the roughness, at the toe of the spillway, there is no need to reduce facility of flow energy like stilling basin, or if necessary, the dimensions of these structures will be reduced. On stepped spillway besides the high amount of energy dissipation leading to a reduction in the size of stilling basin and cost savings, uplift pressure is also reduced.

Three types of flow regimes on stepped spillway with discharge changes can be seen. Nappe flow regime in low flows, with the increase in flow rate, is changed to transitional regime, and with further increase in flow rate, skimming regime can be seen. Sorensen (1985) carried out some research on the stepped spillway hydraulics. Chanson (2001) 
and also Chamani and Rajaratnam (1994) have done a lot of research about the nappe and skimming flow regimes and proposed relationships to determine the extent of energy loss in these types of flow regimes.

Study of numerical methods shows that Cassidy (1965) has been one of the first researchers who calculated the coefficient of discharge and surface profile for flow over standard spillway profiles by using the relaxation technique in complex potential plane. Cassidy (1965) compared the results of numerical and experimental model and showed that there was reasonable correlation between the values obtained from the numerical model and the experimental data. Launder and Spalding (1972) were the first researchers who provide the $k-\varepsilon$ model. In recent years, $k-\varepsilon$ turbulence model is known as an acceptable method for simulating the flow over the stepped spillway. For this reason, this study uses $k-\varepsilon$ turbulence model.

Chen et al. (2002) analyzed the flow over the stepped spillway by using FLUENT software. For simulating the multiphase flow, the volume of fluid (VOF) model was used, and to simulate the turbulence of flow, $k-\varepsilon$ turbulence model was used. Their research showed that there is a reasonable agreement between the numerical and experimental results. Tabbara et al. (2005) modeled the flow over the stepped spillway using ADINA software. For simulating the multiphase flow, the finite element method (FEM) was used, and in order to simulate the turbulence of flow, standard $k-\varepsilon$ turbulence model was used. Tabbara et al. (2005) concluded that the results of the numerical method showed a good correlation with experiments. Musavi Jahromi et al. (2008) studied the flow over the stepped spillway with ANSYS software. They used FEM for simulating the multiphase flow and stated that the results of a numerical method for energy dissipation have only a $6 \%$ difference with experiments. Mansoori et al. (2011) studied on energy loss in stepped spillway equipped with inclined steps and end sill together by FLUENT software. They used VOF method and $k-\varepsilon$ turbulence model for simulating the flow over the stepped spillway. Comparing the energy loss of numerical values with experimental data showed that the difference is acceptable.

Felder and Chanson (2014) tested a pooled stepped spillway in a relatively large-size facility. The flow patterns, the macro- and microscopic air-water flow properties, and the energy dissipation performances were recorded. Results were compared with the flat stepped spillway design for the same chute. Roushangar et al. (2017) investigated energy dissipation over stepped spillways under nappe flow regime using neural networks and neuro-fuzzy approaches. The results showed that the most influential parameters on energy dissipation were identified as critical depth, height and number of steps, respectively. In another study, Roushangar et al. (2018) used gene expression programming (GEP) and support vector machine (SVM) for estimation of discharge coefficient in the stepped spillways. They considered two flow regimes: (i) nappe and (ii) skimming flow regimes. The results showed that for both proposed methods the $F_{r 1}$ and $H / y_{1}$ parameters in nappe flow and $F_{r 1}$ and $R_{e}$ parameters in skimming flow had the most important influence. Valero et al. (2018) studied energy dissipation of a type III basin under design and adverse conditions for stepped and smooth spillways. Results showed that type III basins can perform adequately with a stepped chute despite the effects the steps have on the relative role of each basin element. It was concluded that the classic type III basin design, based upon methodology by reclamation specific to smooth chutes, can be hydraulically improved for the case of stepped chutes for design and adverse flow conditions.

Figure 1 provides stepped spillway of the Opuha embankment dam. The Opuha Dam is located on the Opuha River, a tributary of the Opihi River in South Canterbury, New Zealand. The dam is used for water storage for farming irrigation and provides 7.7 MW of electricity to New Zealand's national grid.

The aim of this study is evaluate the numerical model in estimating energy dissipation in stepped spillway and comparison of numerical and experimental data. Study on rotational behavior of flow through the steps, shear stress and pressures on the steps are the other objectives of this research. Numerical simulation is based on FLUENT software using $k-\varepsilon$ turbulence model.

\section{Materials and methods}

\section{Numerical modeling}

FLUENT software is used in this study to simulate the flow over a stepped spillway. Numerical modeling includes solving Navier-Stokes equations which are based on the laws of continuity and momentum, for any fluid in motion. Continuity and momentum equations, respectively, are expressed in Eqs. (1) and (2):

$\frac{\partial \overline{u_{i}}}{\partial x_{i}}=0$

$\frac{\partial \overline{u_{i}}}{\partial t}+\overline{u_{j}} \frac{\partial \overline{u_{i}}}{\partial x_{j}}=-\frac{1}{\rho} \frac{\partial \bar{p}}{\partial x_{i}}+g_{x_{i}}+\frac{\partial}{\partial x_{j}}\left(v \frac{\partial \overline{u_{i}}}{\partial x_{j}}-\overline{u_{i}^{\prime} u_{j}^{\prime}}\right)$

where $\overline{u_{i}}=$ velocity component in the direction $x_{i}, \nu=$ kinematic viscosity, $t=$ time, $\rho=$ fluid density, $g_{x i}=$ gravitational acceleration components and $\bar{p}=\mathrm{a}$ pressure term at each point of the fluid.

The parameter $\rho \overline{u_{i}^{\prime} u_{j}^{\prime}}$ is the Reynolds stresses which acts on the fluid and applies the effects of the turbulence vortices 
Fig. 1 Stepped spillway of the Opuha embankment dam (Gonzalez and Chanson 2008)

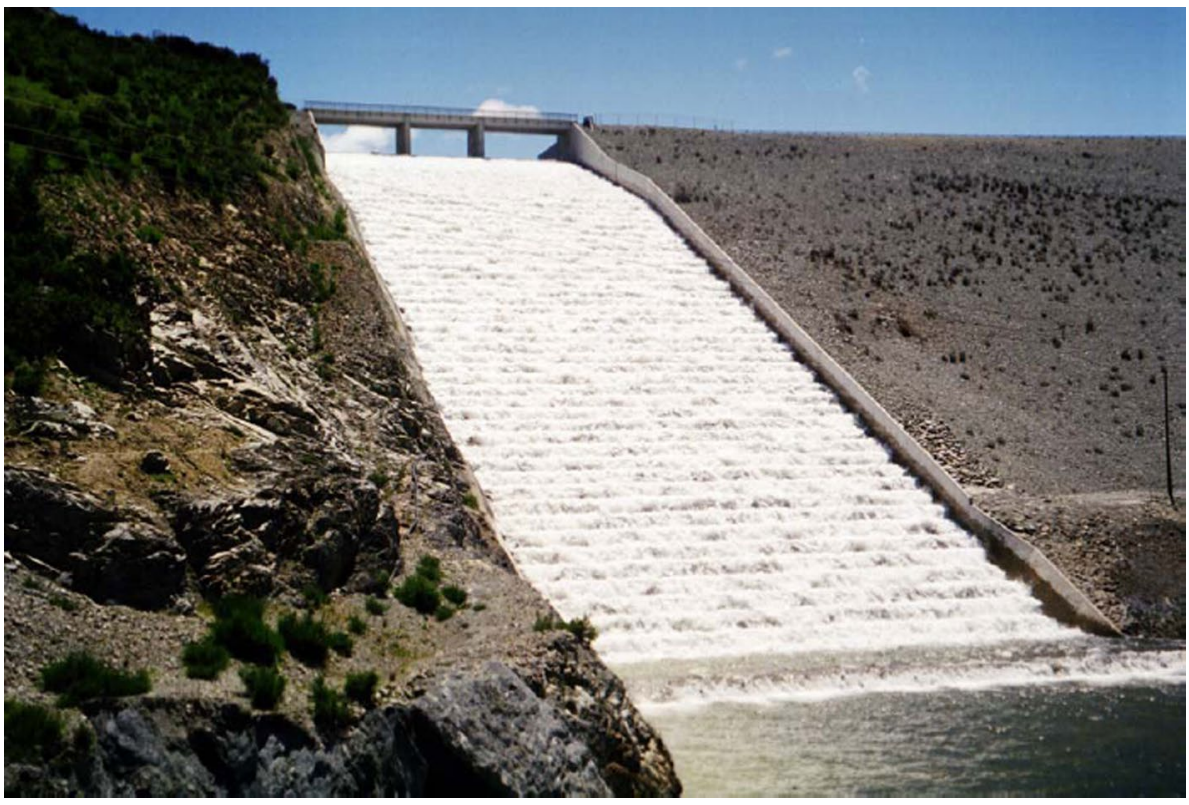

on it. To determine the parameters of the Reynolds stress, a variety of turbulence models can be used. In this study to simulate the turbulent flow, $k-\varepsilon$ turbulence model is employed.

To determine the free-surface flow, VOF model is used. In this method, a variable function named $\alpha$ is used which represents the volume of water in the calculation cell. If $\alpha=1$, it indicates that the cell is full of water and if $\alpha=0$, the cell is filled with air. In the case of $0>\alpha>1$, some percent of cell is water and the rest of it is filled with air. Thus, regarding the free surface of a cell, the free-surface flow can be determined.

\section{Stepped spillway characteristics}

In this research, the results of the numerical method are compared with the results of a research project conducted in the Hydraulics Laboratory, Department of Water Engineering, Faculty of Agriculture, University of Tabriz, Iran. Experiments have been conducted in a rectangular channel with metal-glass materials with length $9 \mathrm{~m}$, width of $25 \mathrm{~cm}$ and height of $50 \mathrm{~cm}$. The physical model of stepped spillway has a width of $25 \mathrm{~cm}$ and height of $30 \mathrm{~cm}$. The number of steps in spillway is 3 with a slope of 2:1 (horizontal to vertical). Therefore, the height of each step is $10 \mathrm{~cm}$ and its horizontal length is $30 \mathrm{~cm}$.

Calibration of the numerical model in this study is based on experimental test data. A number of basic decisions had to be made before the experimental test runs. For instance, the size of step was decided by assuming a model scale of 1:10, which was a reasonable scale in hydraulic structures. This therefore led to determining step heights to be $100 \mathrm{~cm}$ in the full-scale stepped spillway structures. The actual choice of steps in this study was based on practical sizes normally found in prototypes.

The water supply system consists of underground reservoir which is equipped with a pump and a 4-m-tall cylindrical water reservoir (head tank) that supplies water. A weir at the head tank returns extra water from the head tank to the underground reservoir. The flow after the flume reaches a sharp crested triangular weir, and water measurement is taken by this weir. A precise water gauge was used to measure water depth in upstream and downstream of the stepped spillway (Fig. 2). Figures 3 and 4 show flow over physical model of stepped spillway prepared in this study.

\section{Numerical model characteristics of spillway}

To draw a geometric shape of the model and define the boundary conditions, Gambit software was used. In Gambit software, there are various options for mesh generation, which such as them can be pointed to Tri (Triangle), Quad (Quadratic) and Tri/Quad (Triangle/Quadratic). It should be noted that in all models that have been used in this study, Quad element is used for flow field grid. Figure 5 shows the computational grid in models. Also because of high sensitivity, mesh density near the wall and on the surface of spillway is increased. Figure 6 shows the generated mesh for stepped spillway.

Independence of the mesh is one of the important issues in use of numerical models. Mesh density/the number of meshes affects the computational effort. Thus, the optimum mesh number should be selected. The result is mentioned in Table 1. In this table, the amount of root mean square error (RMSE) for a number of meshes is provided. According to

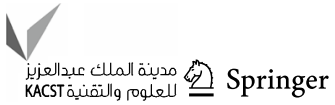




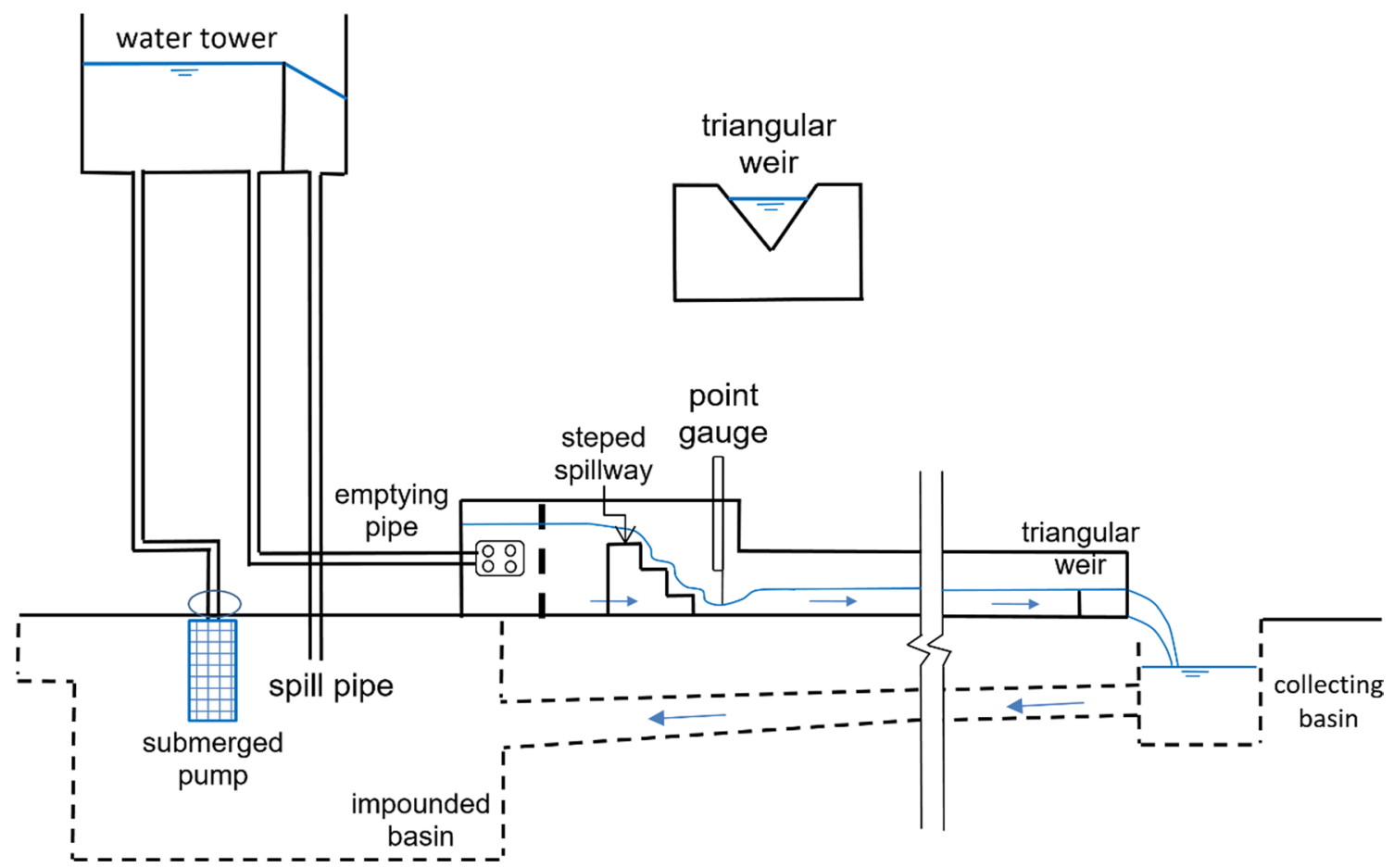

Fig. 2 Schematic representation of the experimental equipments

Fig. 3 Flow over stepped spillway (downstream view)

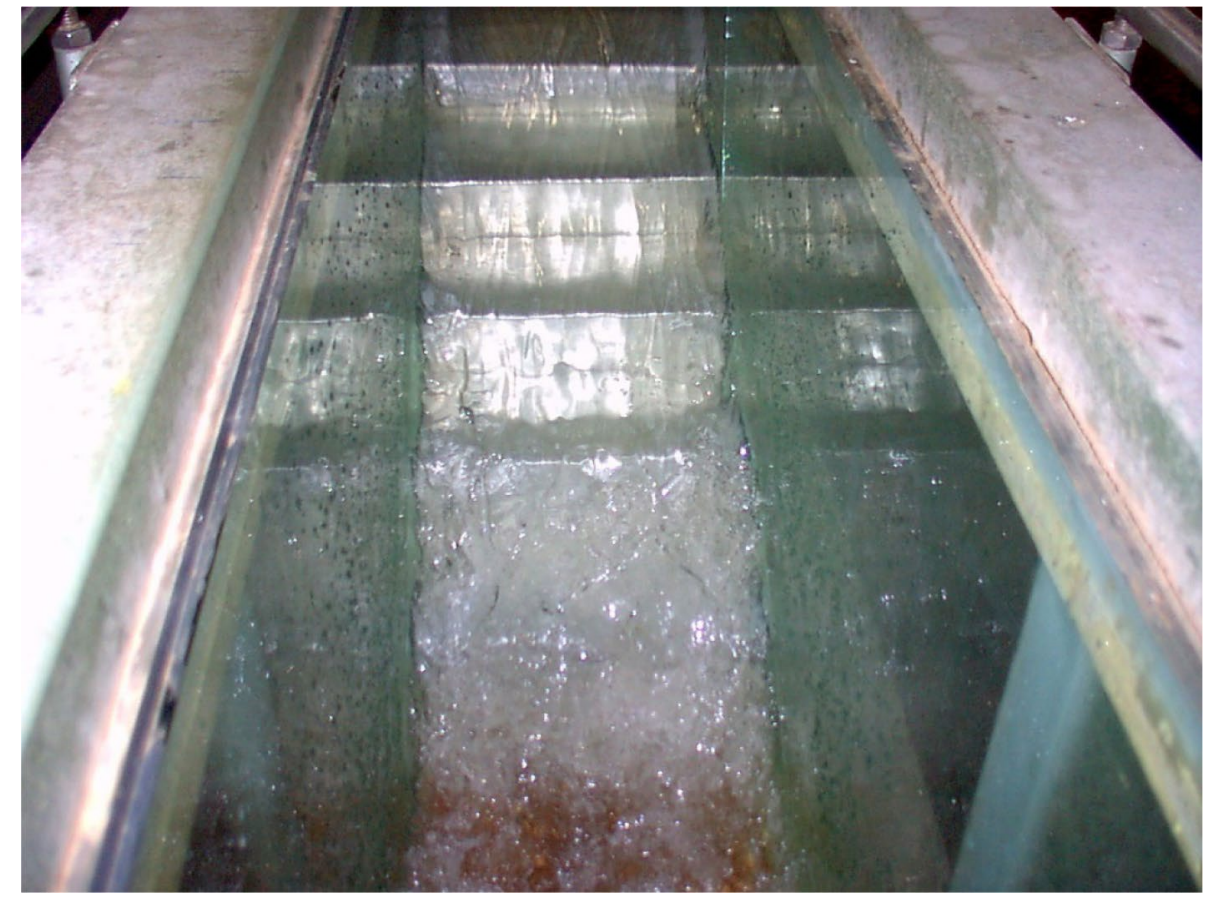

Table 1, meshing number of 60,000 is chosen for the optimum mesh.

Figure 7 shows the boundary conditions for the models. In this study, the walls of the channel and spillway were defined by the wall boundary condition, water depth at the entrance and freeboard of channel defined by velocity inlet condition and output stream face was defined by pressure outlet condition. For evaluating the effects of walls on the flow, standard wall function has been used. Considering the rotational flow on the spillway, RNG $k-\varepsilon$ turbulence model 
Fig. 4 Close-up of flow over stepped spillway (side view), turbulent and energy dissipation in toe of the spillway

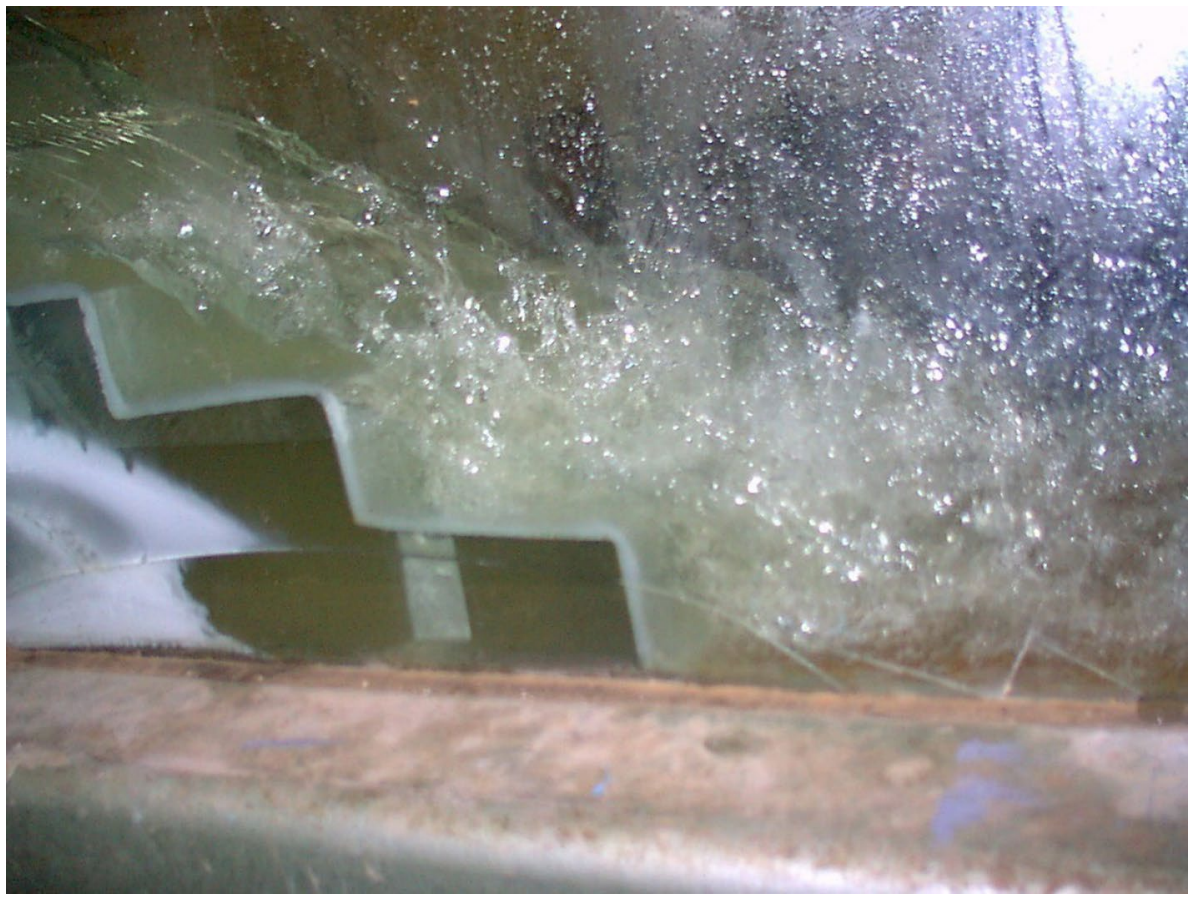

$3.9(\mathrm{~m})$ $0.6(\mathrm{~m})$ $4.5(\mathrm{~m})$

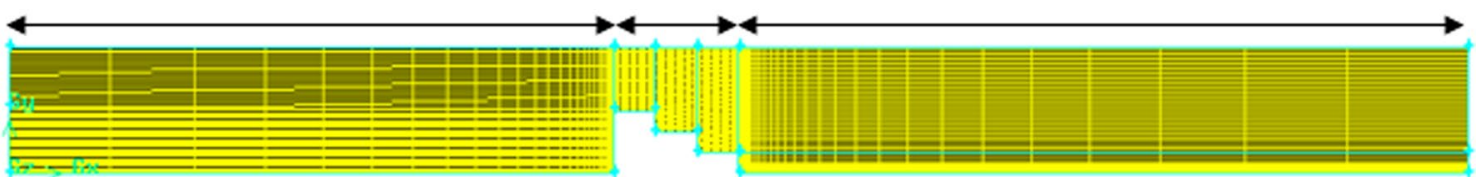

Fig. 5 Upstream and downstream boundary of spillway with mesh generation

Fig. 6 Generated mesh on stepped spillway

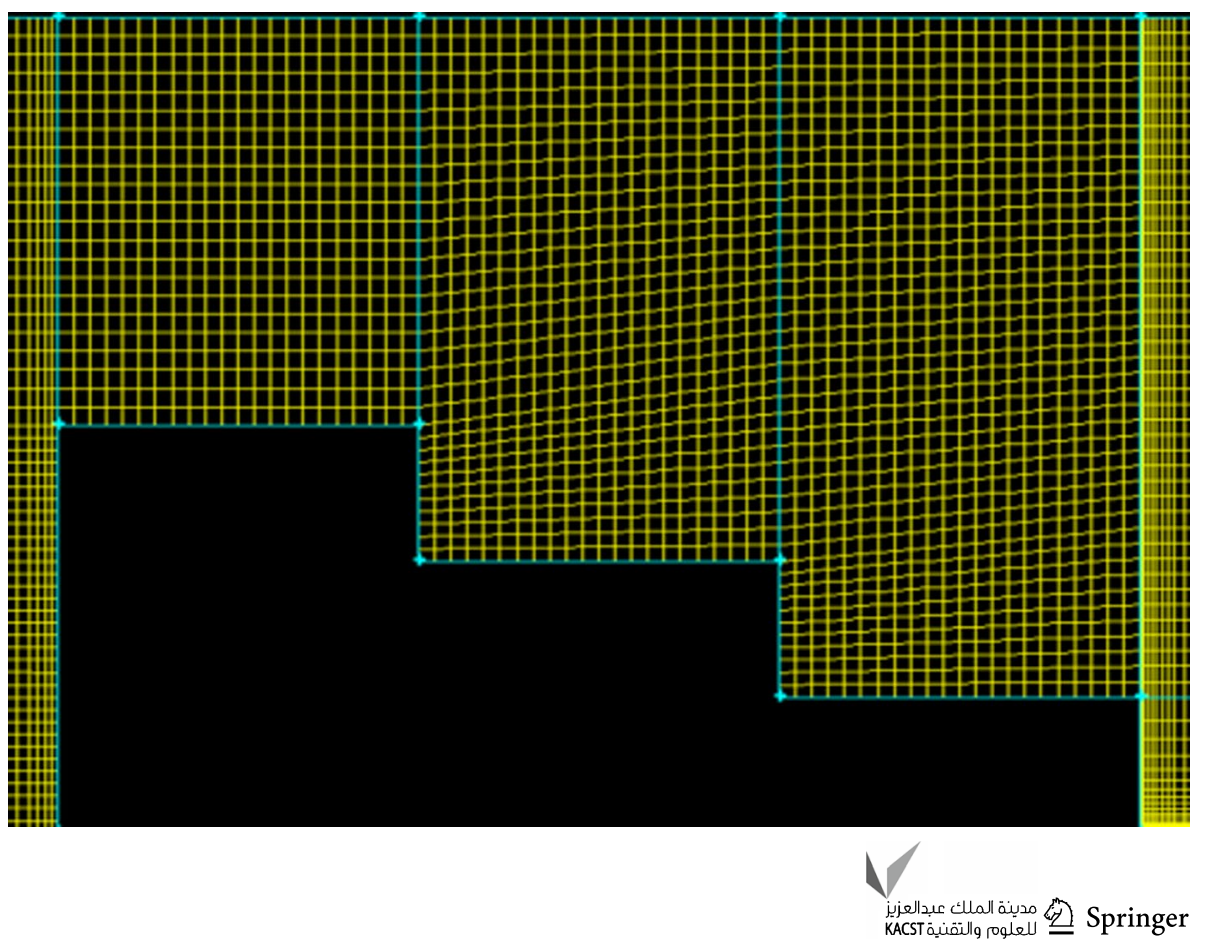


Table 1 Error percentage in selecting optimum mesh

\begin{tabular}{ll}
\hline Mesh number & RMSE $(\mathrm{mm})$ \\
\hline 23,000 & 9.18 \\
44,000 & 6.51 \\
60,000 & 1.67 \\
71,000 & 2.71 \\
\hline
\end{tabular}

was selected for simulation. It is worth mentioning that RNG model is recommended for rotating and curved flows (Fluent 2005).

To complete the process of preparing numerical model, pressure equation was used as body force-weighted. Body force-weighted discretization technique showed the best convergence in this study. Since the flow is modeled as unsteady, for velocity-pressure coupling algorithm we used PISO method, which is recommended for unsteady flows. In this research, the time step was selected as 0.001 to solve the problem.

\section{Results and discussion}

\section{Velocity vectors}

Figure 8 represents a graphical output of the FLUENT software, which indicates the flow on stepped spillway. In this figure, the blue represents the water phase, red represents air phase and green represents the mixing phase.

Figure 9 shows the velocity vectors of flow on stepped spillway. As mentioned earlier, one of the energy dissipation factors in these structures is rotating flow that occurs after each step which is clearly shown in Fig. 9. This rotational flow is formed as clockwise near the walls. The value of velocity in superficial flow is greater than rotational flow

on the steps. Due to the interaction between superficial flow and rotating flow above it, energy dissipation is high. The size of the energy dissipation structures (steps) can be designed based on residual flow over the stepped spillway. Energy ratio or residual energy can be calculated according to kinetic and potential energy in upstream and downstream of the spillway.

\section{Relative energy dissipation}

In order to control the validity of numerical results and also a better understanding of the energy dissipation in various flow rates, in Figs. 10 and 11, the effects of flow on depth at the upstream and downstream of the stepped spillway have been investigated. In these graphs, the results of numerical model have been compared with Salmasi (2009) experiments. It should be noted in that research laboratory studies are conducted on the gabion and rigid stepped spillway, where only the results for the rigid spillway are used. As expected, by increasing the flow rate per unit width $(q)$, the depth of flow at the upstream $\left(y_{\mathrm{u}}\right)$ and downstream $\left(y_{\mathrm{d}}\right)$ sections of spillway increased. According to Figs. 10 and 11, it can be concluded that numerical model with an error of about $3 \%$ has the ability to explore these phenomena. The results of the numerical model have a good agreement with experimental data. Effects of the channel side walls, forces caused by surface tension and viscosity at low discharges and the accuracy of laboratory data are the factors that cause the difference between the numerical and experimental data.

In Fig. 12, the relative energy dissipation versus values of discharge per unit width of the stepped spillway between the physical model and the numerical model is presented. An amount of energy dissipation is calculated using Eq. (3). In this equation, $H_{0}$ is total energy above the spillway crest

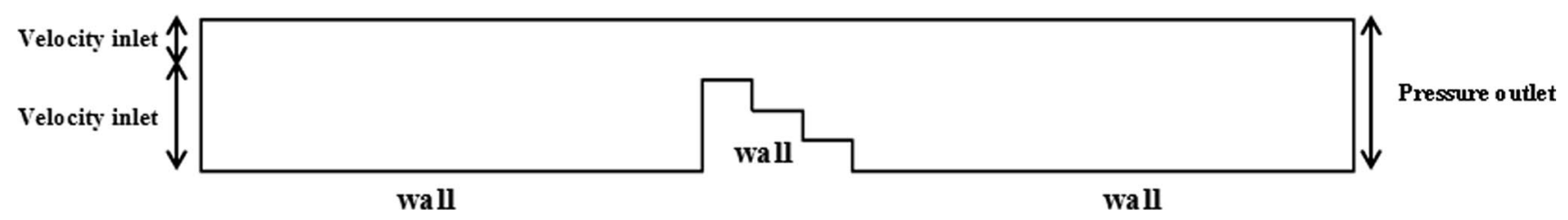

Fig. 7 Boundary conditions imposed on the model

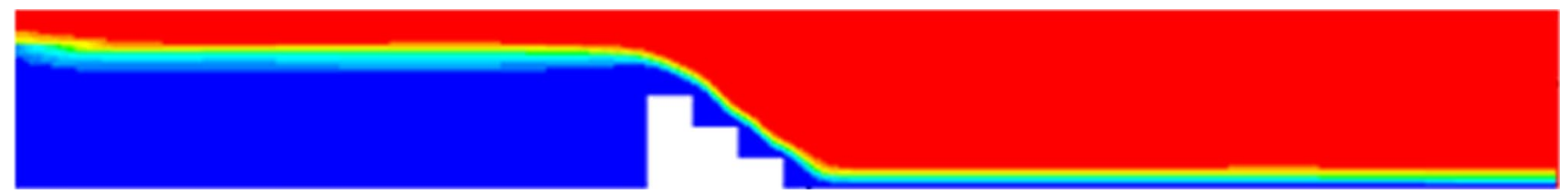

Fig. 8 Simulation of flow on stepped spillway 


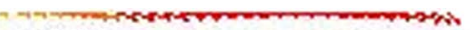

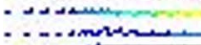

$\because \because \ldots m$

: :,

$\because \because \cdots \cdots$

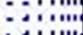

: $: 3: . .$.

.:....

::涼.

:

: $: \cdots . .$.

::.....

: $: \cdots$

::o...

::o.......

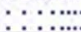

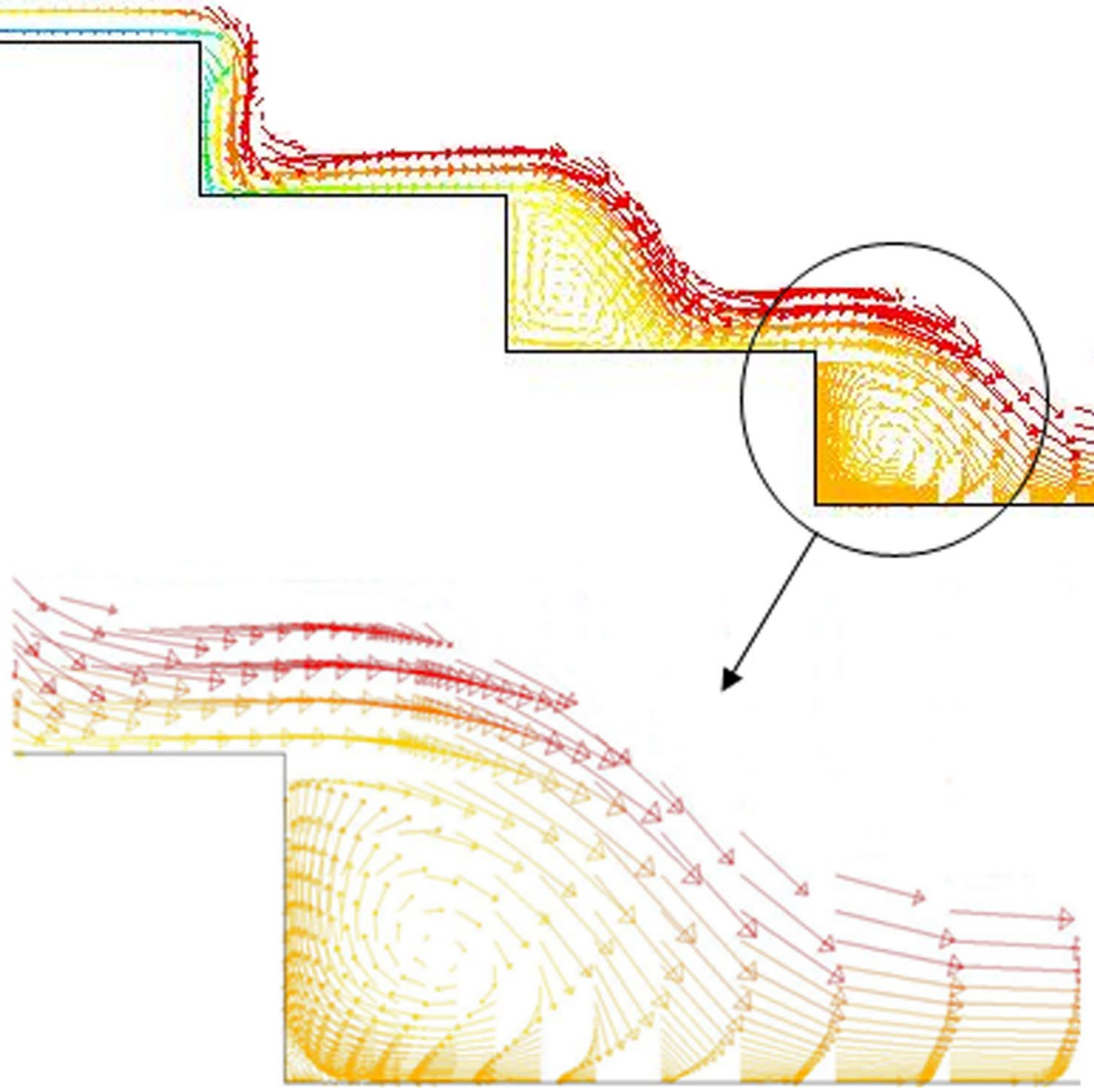

Fig. 9 Velocity vectors on simulated stepped spillway

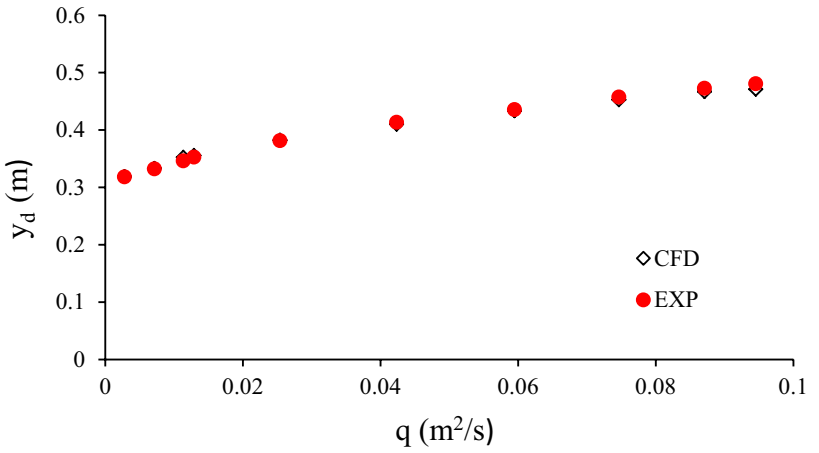

Fig. 10 Changes in water depth in the upstream of spillway against the flow rate

and $H_{1}$ is energy at downstream of the spillway before the hydraulic jump.

$\frac{\Delta H}{H_{0}}=\frac{H_{0}-H_{1}}{H_{0}} \times 100$

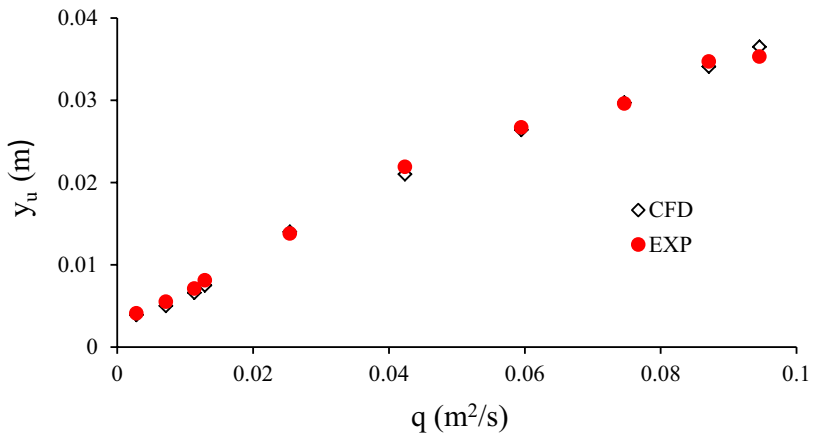

Fig. 11 Changes in water depth in the downstream of spillway against the flow rate

The total energy in upstream of the spillway crest is calculated as follows:

$$
H_{0}=H+y+\frac{V_{\mathrm{a}}^{2}}{2 g}=H+y+\frac{q^{2}}{2 g y^{2}}
$$




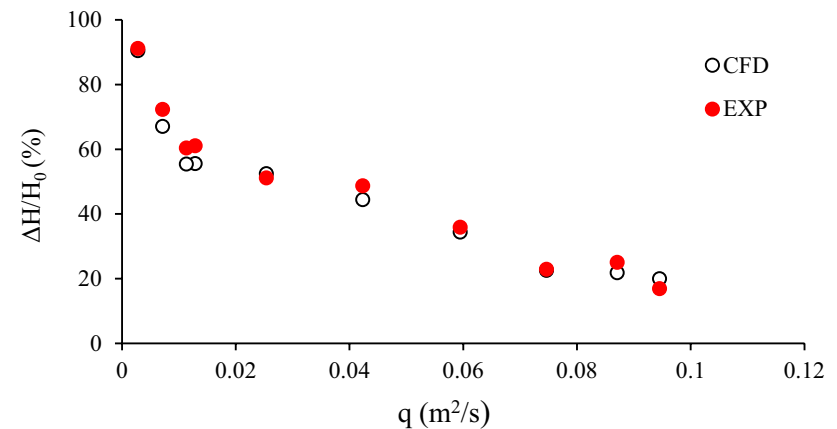

Fig. 12 Comparison of changes in relative energy dissipation versus discharge per unit width on stepped spillway

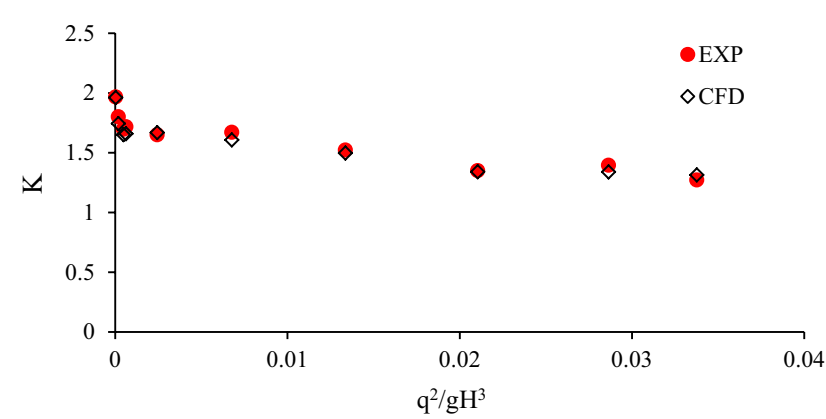

Fig. 13 Relative energy dissipation variations as $K=\left(H_{0}-H_{1}\right) / H_{0}$ versus $q^{2} / g H^{3}$ for stepped spillway

where $H=$ total height of spillway, $y=$ water depth above spillway crest at a distance of about $60 \mathrm{~cm}$ on upstream of the spillway, $g=$ acceleration due to gravity and $V_{\mathrm{a}}=$ approach velocity of water to the spillway. Also $V_{\mathrm{a}}=q /(H+y)$, where $q$ is discharge per unit width of canal/flume.

According to Fig. 12, relative energy dissipation decreases with the increase in the flow rate. In this case, the numerical model error is about $6 \%$ which is negligible and implies better performance of the present numerical model.

For a better understanding and more information of Fig. 12, an attempt has been made to change the scale of the axes. So, dimensionless parameter $q^{2} / g H^{3}$ was used on horizontal axis and dimensionless parameter $K$ on vertical axis, where $K=\left(H_{0}-H_{1}\right) / H_{0}$. The result is presented in Fig. 13 .

Figure 13 shows that energy dissipation over the stepped spillway in the low flow rate is higher than the others. It is noteworthy that, by comparing the values obtained from the numerical model with experiments, numerical model error was determined as about $2 \%$ which is negligible.

For a closer look about the relative energy dissipation over the stepped spillway, in Fig. 14 the effect of the dimensionless parameter $y_{\mathrm{c}} / h$ has been studied, where $h$ is equal to the height of the steps and $y_{\mathrm{c}}$ is critical depth and is calculated from $y_{\mathrm{c}}=\left(q^{2} / g\right)^{1 / 3}$.

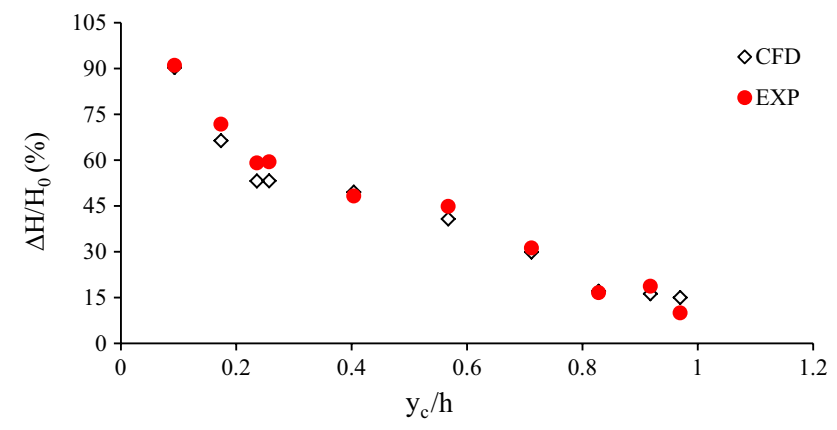

Fig. 14 Effect of dimensionless parameter $y_{\mathrm{c}} / h$ on relative energy dissipation over the stepped spillway

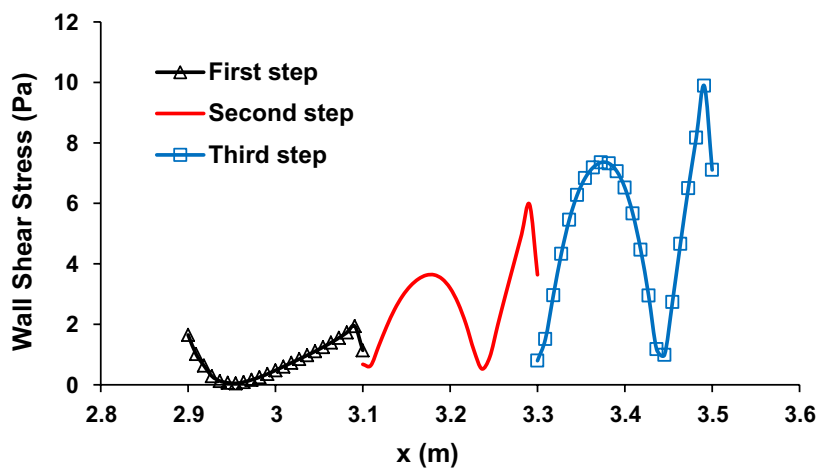

Fig. 15 Variations in shear stress in the maximum flow rate $q=0.0945\left(\mathrm{~m}^{2} / \mathrm{s}\right)$

According to Fig. 14, by increasing $y_{\mathrm{c}} / h$ the relative energy dissipation is reduced. By increasing the flow rate (increasing velocity and Froude number) and thereby increasing the thickness of flow (depth of flow) on the steps, the effect of steps (roughness) on the dissipation gets reduced.

\section{Shear stress}

In Figs. 15, 16 and 17, changes in shear stress $(\tau)$ in three flow rates, maximum $q=0.0945\left(\mathrm{~m}^{2} / \mathrm{s}\right)$, average $q=0.0423$ $\left(\mathrm{m}^{2} / \mathrm{s}\right)$ and minimum, $q=0.0071\left(\mathrm{~m}^{2} / \mathrm{s}\right)$, at the bottom of each step (horizontal surface of steps) are compared.

Based on Figs. 15, 16 and 17 by decreasing flow, shear stress on the steps is reduced. In maximum flow rate, variations in the second and third steps are almost identical so that until the middle of these steps, the shear stress increases and then decreases, and then, again we are seeing an increasing trend. Finally, at the edge of the steps, this amount decreases suddenly that it can be attributable to flow jump and separation of flow from step, ultimately reducing the shear stress on this section. This process was observed almost in all steps and on all three flow rates. Another thing that is worth mentioning is different behavior of shear stress 


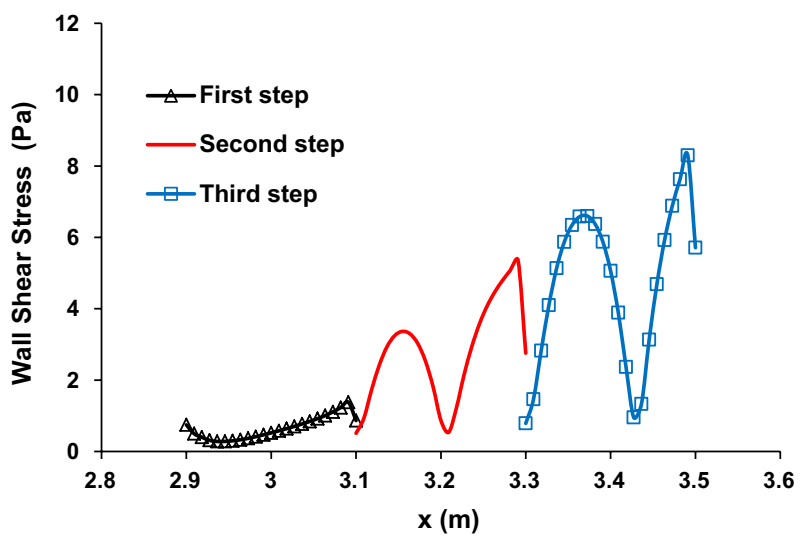

Fig. 16 Variations in shear stress in the average flow rate $q=0.0423$ $\left(\mathrm{m}^{2} / \mathrm{s}\right)$

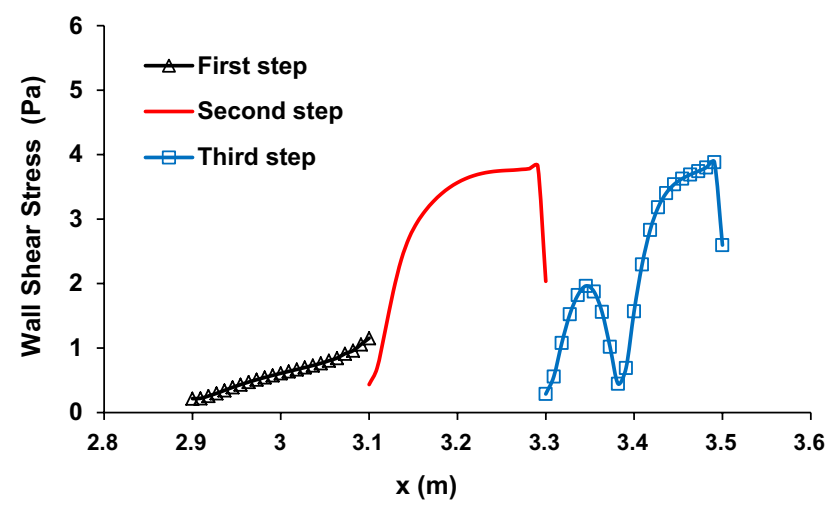

Fig. 17 Variations in shear stress in the minimum flow rate $q=0.0071\left(\mathrm{~m}^{2} / \mathrm{s}\right)$

on the first step toward the second and third steps. Over this step, shear stress is initially reduced and then increased, and at the lowest flow rate, this process takes a special discipline and will be in uptrend. The reason can be attributed to the adhesion flow on the steps. Because in the high flow rate, flow more quickly and with less downtime on the steps that will ultimately lead to a reduction in shear stress, while at lower flows flow on the step bind and therefore the shear stress increases. In Table 2, the values of shear stress along the stepped spillway are provided.

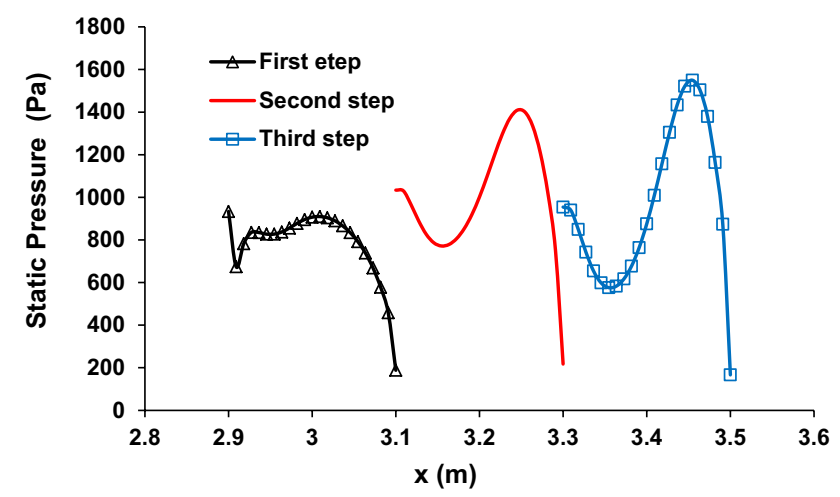

Fig. 18 Pressure distribution on the stepped spillway for maximum flow rate $q=0.0945\left(\mathrm{~m}^{2} / \mathrm{s}\right)$

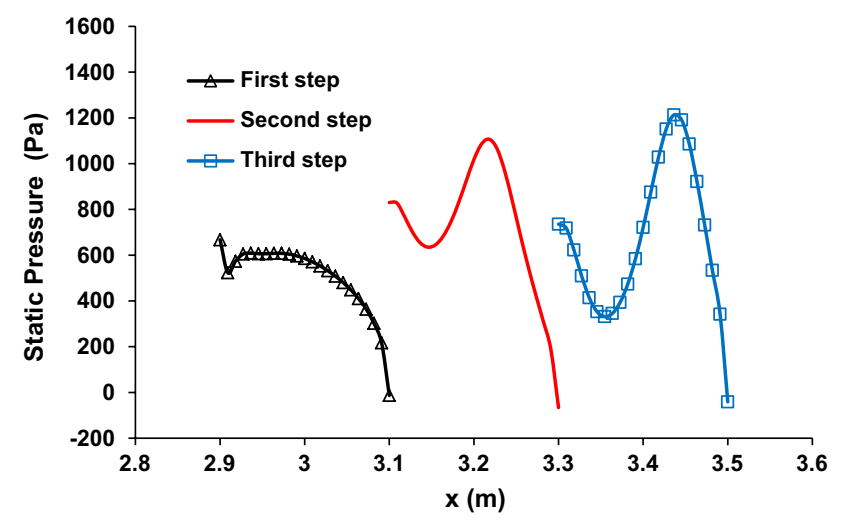

Fig. 19 Pressure distribution on the stepped spillway for average flow rate $q=0.0423\left(\mathrm{~m}^{2} / \mathrm{s}\right)$

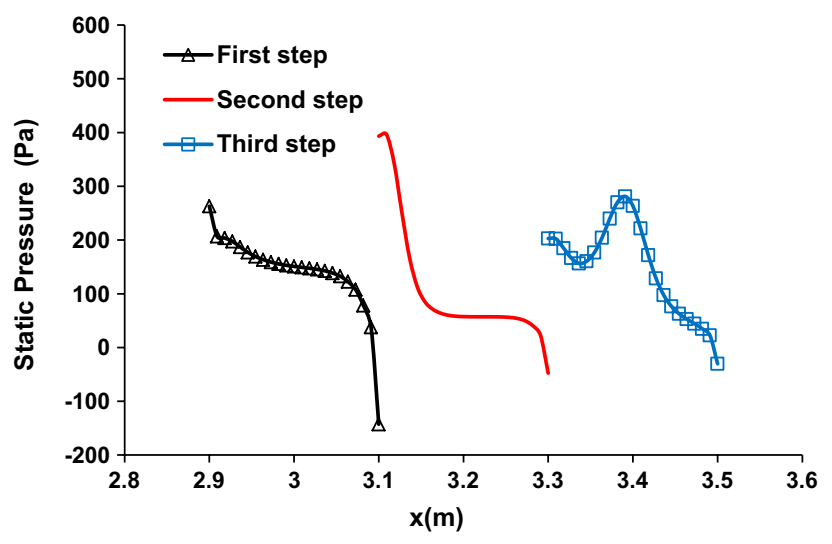

Fig. 20 Pressure distribution on the stepped spillway for minimum flow rate $q=0.0071\left(\mathrm{~m}^{2} / \mathrm{s}\right)$

Table 2 Maximum and minimum values of shear stress on the steps

\begin{tabular}{|c|c|c|c|c|c|c|c|c|c|}
\hline & \multicolumn{3}{|c|}{$\begin{array}{l}\text { Maximum flow } \\
q=0.0945\left(\mathrm{~m}^{2} / \mathrm{s}\right)\end{array}$} & \multicolumn{3}{|c|}{$\begin{array}{l}\text { Average flow } \\
q=0.0423\left(\mathrm{~m}^{2} / \mathrm{s}\right)\end{array}$} & \multicolumn{3}{|c|}{$\begin{array}{l}\text { Minimum flow } \\
q=0.0071\left(\mathrm{~m}^{2} / \mathrm{s}\right)\end{array}$} \\
\hline & First step & Second step & Third step & First step & Second step & Third step & First step & Second step & Third step \\
\hline Maximum shear stress $(\mathrm{Pa})$ & 1.94 & 5.96 & 9.89 & 1.38 & 5.36 & 8.30 & 1.15 & 3.83 & 3.88 \\
\hline Minimum shear stress $(\mathrm{Pa})$ & 0.05 & 0.53 & 0.80 & 0.28 & 0.51 & 0.79 & 0.22 & 0.43 & 0.29 \\
\hline
\end{tabular}


Table 3 Minimum amount of pressure on the steps

\begin{tabular}{|c|c|c|c|c|c|c|c|c|c|}
\hline & \multicolumn{3}{|c|}{$\begin{array}{l}\text { Maximum flow } \\
q=0.0945\left(\mathrm{~m}^{2} / \mathrm{s}\right)\end{array}$} & \multicolumn{3}{|c|}{$\begin{array}{l}\text { Average flow } \\
q=0.0423\left(\mathrm{~m}^{2} / \mathrm{s}\right)\end{array}$} & \multicolumn{3}{|c|}{$\begin{array}{l}\text { Minimum flow } \\
q=0.0071\left(\mathrm{~m}^{2} / \mathrm{s}\right)\end{array}$} \\
\hline & First step & Second step & Third step & First step & Second step & Third step & First step & Second step & Third step \\
\hline Maximum pressure $(\mathrm{Pa})$ & 933.72 & 1409.39 & 1549.72 & 667.21 & 1106.48 & 1212.96 & 262.88 & 396.51 & 281.21 \\
\hline Minimum pressure $(\mathrm{Pa})$ & 188.18 & 217.46 & 166.58 & -12.85 & -65.95 & -41.07 & -142.72 & -47.57 & -30.29 \\
\hline
\end{tabular}

\section{Pressure profiles}

In Figs. 18, 19 and 20, pressure profiles in the horizontal surfaces of the three steps are, respectively, visible for the three flow rates.

In both maximum and average flow rates, pressure on the horizontal surface of steps initially decreases and then increases, and again at the edge of step, it is reduced. In minimum flow rate uptrend noted in the previous cases occurred less so that almost a reduction trend of pressure distribution was observed. The lowest pressure calculated by simulation is an important component of continuous pressure, and the minimum average pressure is needed to assess the potential for the formation of cavitation. Quantitative analysis of these parameters is presented in Table 3 .

\section{Conclusion}

By observations from the modeling which was performed, with the increase in flow rate relative energy dissipation will be reduced over the spillway. In this context, use of appropriate dimensionless parameters in the analysis of the results is recommended. By simulating the flow depth in upstream and downstream of the spillway, differences between the results of experiments and numerical modeling were reported appropriate and acceptable, and with the validation on the numerical model, it is identified that FLUENT software has a high potential in the evaluation of energy dissipation in stepped spillway so that the flow depth error and consequently amount of energy dissipation are calculated, about $3 \%$ of which is acceptable. So numerical modeling is recommended for simulation of the flow over stepped spillway, due to savings in time and cost. Then extracted velocity vectors in exchange for different flow rate and rotational flow that represent true nature of this type of spillway were observed clearly. Also on reviewing shear stress and pressure on each step it was determined that by increasing the flow, shear stress and pressure are reduced.

Open Access This article is distributed under the terms of the Creative Commons Attribution 4.0 International License (http://creativeco mmons.org/licenses/by/4.0/), which permits unrestricted use, distribution, and reproduction in any medium, provided you give appropriate credit to the original author(s) and the source, provide a link to the Creative Commons license, and indicate if changes were made.

\section{References}

Cassidy JJ (1965) Rotational flow over spillway of finite height. J Hydraul Eng ASCE 91(6):155-173

Chamani MR, Rajaratnam N (1994) Jet flow on stepped spillways. J Hydraul Eng ASCE 121(2):254-259

Chanson H (2001) Hydraulic design of stepped spillway and downstream energy dissipaters. Dam Eng 11(4):205-242 ISSN: $061700563 X$

Chen Q, Dai G, Liu H (2002) Volume of fluid model for turbulent numerical simulation of stepped spillway over flow. J Hydraul Eng ASCE 128(70):683-688

Felder S, Chanson H (2014) Effects of step pool porosity upon flow aeration and energy dissipation on pooled stepped spillways. J Hydraul Eng 140:(4). https://doi.org/10.1061/(ASCE)HY.19437900.0000858

Fluent (2005) Version 6.2 user's guide. Fluent Inc group. Salt Lake City, Utah, US.

Gonzalez CA, Chanson H (2008) Hydraulic design of stepped spillways and downstream energy dissipators for embankment dams. Dam Eng XVVII(4):104

Launder BE, Spalding DB (1972) Lectures in mathematical model of turbulent. Academic, London

Mansoori A, Hamedi AM, Malek Mohamadi I, Roshanaei H (2011) Determination of energy loss in stepped spillway equipped with inclined steps and end sill together by fluent numerical model. In: Conference on world renewable energy congress, Linkoping, Sweden, pp 8-11

Musavi Jahromi H, Bina M, Salmasi F (2008) Physical and numerical modeling of the nappe flow in the stepped spillway. J Appl Sci 8(9):1720-1725

Roushangar K, Akhgar S, Salmasi F, Shiri J (2017) Neural networks- and neuro-fuzzy-based determination of influential parameters on energy dissipation over stepped spillways under nappe flow regime. ISH J Hydraul Eng 23(1):57-62. https://doi. org/10.1080/09715010.2016.1235472

Roushangar K, Akhgar S, Salmasi F (2018) Estimating discharge coefficient of stepped spillways under nappe and skimming flow regime using data driven approaches. Flow Meas Instrum 59(2018):79_ 87. https://doi.org/10.1016/j.flowmeasinst.2017.12.006

Salmasi F (2009) Energy dissipation in stepped gabion spillway. Final report of research project, Agricultural faculty, University of Tabriz, Tabriz, Iran

Sorensen RM (1985) Stepped spillway hydraulic model investigation. J Hydraul Eng ASCE 111(12):1461-1472

Tabbara M, Chatila J, Awwad R (2005) Computational simulation of flow over stepped spillway. J Comput Struct 83:2215-2224 
Valero D, Bung DB, Crookston BM (2018) Energy dissipation of a type III basin under design and adverse conditions for stepped and smooth spillways. J Hydraul Eng. https://doi.org/10.1061/(ASCE) HY.1943-7900.0001482
Publisher's Note Springer Nature remains neutral with regard to jurisdictional claims in published maps and institutional affiliations. 